\title{
Indoor Radon Concentrations in Al-Hasahisa and Rufaa Towns in the Central Part of Sudan
}

\begin{abstract}
Abd-Elmoniem Ahmed ELZAIN
Abstract: Indoor radon was systematically surveyed in the towns of Al Hasahisa and Rufaa in the central part of Sudan. The radon concentrations were measured in 276 measurements, using CR-39 etched track detectors. The radon concentration in the corresponding towns was found to vary from $(86 \pm 10) \mathrm{Bqm}^{-3}$ in Al-Hasahisa to $(66 \pm 8) \mathrm{Bqm}^{-3}$ in Rufaa. Assuming an indoor occupancy factor of 0.8 and 0.4 for the equilibrium factor of radon indoors, we found that the effective dose rate from $222 \mathrm{Rn}$ in the studied towns ranges from $(2.18 \pm 0.26)$ to $(1.67 \pm 0.20)$ $\mathrm{mSv} \mathrm{y}^{-1}$ and the relative lung cancer risk (RRLC) for radon exposure was 1.078 to $1.059 \%$ in $\mathrm{Al}$ Hasahisa and Rufaa towns respectively. The recorded values of indoor radon concentration in this study are much lower than the radon action level as recommended by ICRP-1993, lower than the new reference level set by WHO and below the action level recommended by the Environmental Protection Agency (EPA). The values of the radon effective dose rate in this survey are slightly larger than the "normal" background level as quoted by UNSCEAR-2000, but way below even the lower limit of the recommended action level as reported by the ICRP1993. The reported values of RRLC are almost negligible.
\end{abstract}

Keywords: Indoor Radon, Effective dose, CR-39, Relative risk of Lung cancer.

\section{Introduction}

Radon gas is recognized as the most significant natural source of human exposure and the leading cause of lung cancer incidence, with the exception of tobacco. The contribution to the mean effective dose equivalent from inhalation of 222Rn and its short-lived decay products $\left({ }^{218} \mathrm{Po},{ }^{214} \mathrm{~Pb},{ }^{214} \mathrm{Bi}\right.$ and $\left.{ }^{214} \mathrm{Po}\right)$ has been estimated to be about $50 \%$ of the total effective dose equivalent from all natural radiation sources [1].

The interest in studying radon behavior is mainly due to the fact that it can accumulate indoors, and in case of entering the body can be serious damage to human respiratory

Manuscript received May 13, 2018; accepted October 21, 2018.

Abd-Elmoniem Ahmed ELZAIN is with the Department of Physics, University of Kassala, Kassala, P.O.Box: 266, Sudan 
and gastrointestinal. Indoor radon measurements are generally associated with dwellings. However, radon exposure shows an extreme variation from location to location and from season to season depending on the surrounding environment $[2,3,4,5,6]$.

There are many sources contributing the variation of indoor radon these sources are soil [7, 8, 9, 10], building materials (rocks, cement, gravel, clay, sand, etc.) [11], surface and ground water sources [12, 13], natural energy sources like (gas, coal, etc.) [14]. Based on the National Academy of Science BEIR VI Report, the US Environmental Protection Agency estimates that about 21,000 annual lung cancer deaths are radon related [15]. The risk is reported to be proportional to the radon level down to the Environmental Protection Agency (EPA), which suggests intervention in residences with concentration values above 148 Bq. $\mathrm{m}^{-3}$ [16]. EPA also concluded that the effects of radon and cigarette smoking are synergistic, so that smokers are at higher risk from radon, from which it can be concluded that radon is the second leading cause of lung cancer after smoking [17]. The World Health Organization recommends that indoor concentrations must be less than 100 Bq. $\mathrm{m}^{-3}$ but warns that if this is not possible, the limit should be taken as $300 \mathrm{~Bq} \cdot \mathrm{m}^{-3}[18]$. The ICRP, 1993 sets limits for the indoor concentrations as follows: normal 200Bq. ${ }^{-3}$, attention (200-400) $\mathrm{Bqm}^{-3}$, remediation (400-600) Bq. ${ }^{-3}$, and intervention that is higher than $600 \mathrm{Bqm}^{-3}$ [19].

Solid-state nuclear track detectors have been widely used for passive measurements of indoor radon and their alpha emitting decay products. The use of CR-39 plastic track detector in air volume of cups has become the most reliable procedure for time integrated, long measurements of radon and their daughters activity concentration under different environmental condition [20, 21, 22].

Many investigations carried out in selected regions to study radon concentration in soil, building materials, water and indoor air in some parts of Sudan $[3,4,5,7,8,9,11,12$, $13,21,23,24]$. In this study, effort has been taken to estimate indoor radon concentration from (276) measurements from Al Hasahisa town (143 measurements) and Rufaa town (133 measurements) in the central part of Sudan (fig. 1).

\section{Materials and methods}

\subsection{The study area}

Indoor radon measurements were determined in two towns that located at the central part of Sudan at Gezira State. These towns are namely; Al-Hasahisa town which lies between $1444^{\prime} \mathrm{N}$ and $33^{\circ} 18^{\backslash} \mathrm{E}$, and Rufaa town which situated at $14^{\circ} 7 / \mathrm{N}$ and $33^{\circ} 35^{/} \mathrm{E}$ both of the towns are about $120 \mathrm{kms}$ from Khartoum town the capital of the Sudan, because they are located at the two banks of blue Nile River Al-Hasahisa at the western bank and Rufaa at the eastern bank of the River). The area at which these towns are located is the most agriculturally productive state in the Sudan (Gezira State). The position of these towns is 
inside the Gezira State, which lies between the Blue Nile and White Nile rivers; this state is bounded by Khartoum state in the North, Gadarif state in the East, White Nile state in the West and Sennar state in the South. It lies between latitude 13-15.20 N and longitude 32.5$340 \mathrm{E}$.

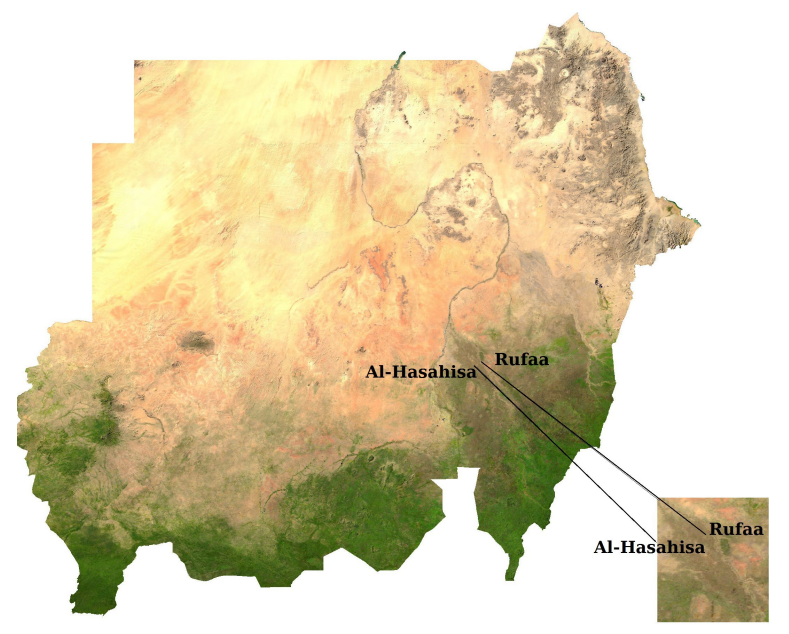

Fig. 1. The map showing the study area of Al-Hasahisa and Rufaa towns that belonging to the Gezira State in the central part of Sudan

\subsection{The type of aggregate materials in Rufaa and Al Hasahisa towns}

The most common aggregate materials appear in the buildings of Al-Hasahisa town and Rufaa town are red brick, mud and concrete materials. The towns are at connected by a bridge constructed through the blue Nile river. There are many types of ventilation systems where some of the buildings use the roof fans and others use the air condition machines while others use the natural ventilation by opening the doors and windows frequently through the most time of the day. Through our survey period, we noticed that some of the inhabitants use concrete mixture (cement, sand bricks, dolomite and concrete) to construct their buildings. Most of the old buildings at these towns were seen to be constructed from clay and gravel materials. The buildings are at height of 2.0 to $4.0 \mathrm{~m}$ from the surface of each building. Each house has many rooms (between two to four) with common no decorated walls, in these rooms the inhabitants are stay most of the day time inside to take rest and in addition to their routine lifestyle.

In this work a precalibrated passive dosimeters containing solid-state nuclear track detectors using allyl diglycol carbonate of super grade quality CR-39 SSNTD, were used to 
study the indoor radon concentrations inside the buildings at Al-Hasahisa and Rufaa towns in the central part of Sudan (Gezira State). These passive dosimeters used here are similar to those we have used in previous studies $[2,4,5,24]$.

The total number of measurements is 276 at the selected sampling positions in the study area at Al-Hasahisa and Rufaa towns. After three months, the dosimeters were collected and chemically etched using a $30 \%$ solution of $\mathrm{KOH}$ at a temperature of $(70.0 \pm 0.1) \mathrm{oC}$ for nine hours. An optical microscope was used to count the number of tracks per $\mathrm{cm}^{2}$ recorded on each detector used. The track density was determined and converted into activity concentration $\mathrm{CRn}$ (in $\mathrm{Bq} \mathrm{m}^{-3}$ ) using the following equation $[11,25]$ :

$$
C_{R n}=\frac{\rho}{K T}
$$

Where $\rho_{R n}$ is, the track density (tracks per $\mathrm{cm}^{2}$ ), $\mathrm{K}_{R n}$ is the calibration constant was previously determined to be $\mathrm{K}_{R n}=4.824 \times 10^{-3}$ tracks $\mathrm{cm}^{-2} \mathrm{~h}^{-1} /\left(\mathrm{Bq} \mathrm{m}^{-3}\right)$ [24] , and $\mathrm{t}$ is the exposure time.

\subsection{Effective Dose and Relative risk of lung cancer estimations}

In order to estimate the radon effective dose rate (ED) that expected to be received by the inhabitants at these towns due to radon gas, the conversion coefficient from the absorbed dose and the indoor occupancy factor has to be taken into account. In the UNSCEAR-2000 report, the committee recommended to use $9.0 \mathrm{nSv} \mathrm{h}^{-1}$ per Bqm$^{-3}$ for the conversion factor $\left(\mathrm{D}_{f}\right)$ (effective dose received by adults per unit ${ }^{222} \mathrm{Rn}$ activity per unit of air volume), 0.4 for the equilibrium factor of radon indoors $\left(\mathrm{E}_{f}\right)$ and 0.8 for the indoor occupancy factor $\left(\mathrm{O}_{f}\right)$. We used the following formula to calculate the effective dose rate [1]:

$$
E D\left(m S v y^{-1}\right)=C_{R n} D_{f} O_{f} E_{f} \times 24 \times 365 \times 10^{-6}
$$

The relative risk of lung cancer (RRLC) due to indoor exposure to radon was calculated using the equation $[4,24,26]$ :

$$
R R L C=e^{\left(0.00087352 \times C_{R n}\right)}
$$

\section{Results and disscussions}

In this study, we present results of the radon concentration levels, effective dose (ED) and relative risk of lung cancer (RRLC) in buildings of Al-Hasahisa and Rufaa towns.

Table 1. and Figures 2-4. Shows the range and average values of indoor radon concentration $\left(\mathrm{Bqm}^{-3}\right)$, effective dose (ED) $\left(\mathrm{mSvy}^{-1}\right)$, and relative risk of lung cancer (RRLC) (\%), for the buildings in Alsaffa Area and Eastern Area at Al-Hasahisa town. The recorded values were found to be from $(119 \pm 15)$ to $(50 \pm 6) \mathrm{Bqm}^{-3}, 1.27$ to $3.01 \mathrm{mSvy}^{-1}$ and 
1.045 to $1.110 \%$, while the average values are found to be $(86 \pm 10) \mathrm{Bqm}^{-3},(2.18 \pm 0.26)$ $\mathrm{mSvy}^{-1}$, and $1.078 \%$, respectively.

Table 1. Summary statistic of indoor radon concentrations measurements, effective dose and radon relative lung cancer risk in AlHasahisa town in the central part of Sudan (Gezira State).

\begin{tabular}{ccccccc}
\hline \hline Residential Area & No. Meas. & $\begin{array}{l}\text { Min. Con. } \\
\left(\mathrm{Bqm}^{-3}\right)\end{array}$ & $\begin{array}{l}\text { Max. Con. } \\
\mathrm{Bqm}^{-3}\end{array}$ & $\begin{array}{l}\text { Aver Con. } \\
\mathrm{Bqm}^{-3}\end{array}$ & $\begin{array}{l}\text { ED } \\
\left.(\mathrm{mSvy})^{-1}\right)\end{array}$ & RRLC\% \\
\hline \hline Eastern Area & 18 & 16 & 87 & $50 \pm 6$ & $1.27 \pm 0.16$ & 1.045 \\
\hline \hline Arkauiet Area & 19 & 55 & 171 & $115 \pm 13$ & $2.90 \pm 0.32$ & 1.106 \\
\hline \hline Alsadaqa Area & 19 & 42 & 152 & $94 \pm 10$ & $2.37 \pm 0.26$ & 1.086 \\
\hline \hline Alimtidad Area & 16 & 34 & 109 & $73 \pm 8$ & $1.85 \pm 0.21$ & 1.066 \\
\hline \hline Alfayha Area & 17 & 47 & 162 & $102 \pm 13$ & $2.58 \pm 0.32$ & 1.094 \\
\hline \hline Alsaffa Area & 19 & 39 & 194 & $119 \pm 15$ & $3.01 \pm 0.37$ & 1.110 \\
\hline \hline Alzhoor Area & 17 & 27 & 86 & $54 \pm 8$ & $1.37 \pm 0.21$ & 1.049 \\
\hline \hline Almazad Area & 18 & 36 & 133 & $82 \pm 10$ & $2.06 \pm 0.26$ & 1.074 \\
\hline \hline Overall & 143 & 16 & 171 & $86 \pm 10$ & $2.18 \pm 0.26$ & 1.078 \\
\hline \hline
\end{tabular}

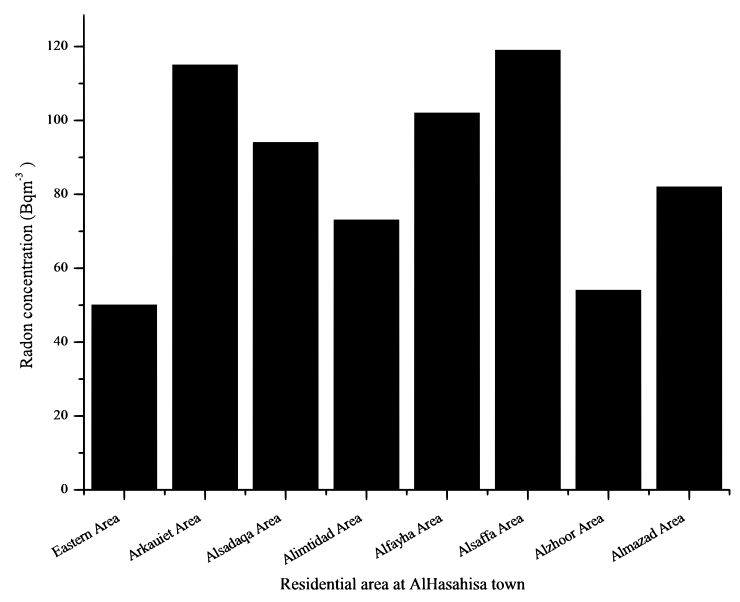

Fig. 2. Indoor radon concentration vs residential areas at AlHasahisa town.

Table 2. and Figures 5-7. Shows the range and average values of indoor radon concentration $\left(\mathrm{Bqm}^{-3}\right)$, effective dose (ED) $\left(\mathrm{mSvy}^{-1}\right)$, and relative risk of lung cancer (RRLC) (\%), for the buildings in Alhisynab Area and Area number 5 at Rufaa town. The calculated values were ranging from $(98 \pm 10)$ to $(66 \pm 8) \mathrm{Bqm}^{-3}, 1.11$ to $2.48 \mathrm{mSvy}^{-1}$ and 1.039 to $1.090 \%$, while the average values are found to be $(86 \pm 10) \mathrm{Bqm} \pm,(1.67 \pm 0.20) \mathrm{mSvy}^{-1}$, and $1.059 \%$, respectively.

From these results we can find that, radon concentration levels, effective dose (ED) and relative risk of lung cancer (RRLC) are in general quite larger in AlHasahisa town 


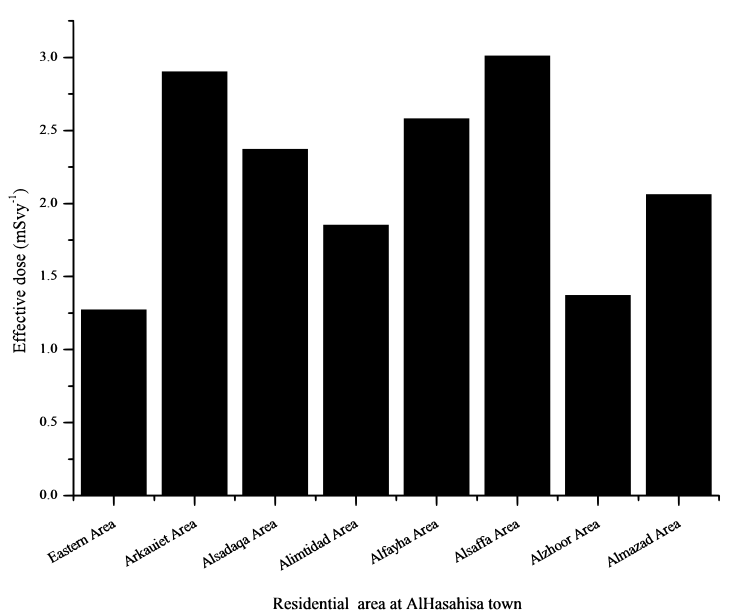

Fig. 3. Effective dose vs residential areas at AlHasahisa town.

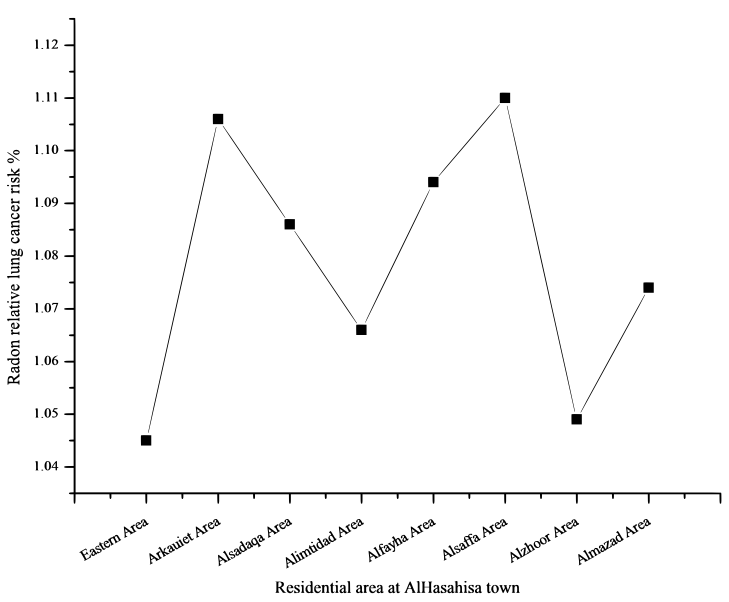

Fig. 4. Radon relative lung cancer risk vs residential areas at AlHasahisa town.

than the values that obtained from the areas in Rufaa town. The higher values of indoor radon concentration, effective dose (ED) and relative risk of lung cancer (RRLC), may be attributed to that Alhisynab Area (AlHasahisa town), is the one of the oldest areas in the town, the buildings are constructed from bricks and mud in addition to that the dwellings are close to each other. The ventilation rate is not good due to the reason of that the buildings of the area are very old; whatever the windows are very small and they are usually closed. The bad ventilation rates received by the inhabitants of these buildings resulting in increasing the concentration values of the area. In Alsaffa Area (Rufaa town), some of the area buildings are noticed to be constructed from brick with cemented materials. These areas are also to some extent nearer to the Blue Nile River bank hence its soil classified as being belonged 
Table 2. Summary statistic of indoor radon concentrations measurements, effective dose and radon relative lung cancer risk in Rufaa town in the central part of Sudan (Gezira State).

\begin{tabular}{lllllll}
\hline \hline Residential Area & No. Meas. & $\begin{array}{l}\text { Min. Con. } \\
\left(\mathrm{Bqm}^{-3}\right)\end{array}$ & $\begin{array}{l}\text { Max. Con. } \\
\left(\mathrm{Bqm}^{-3}\right)\end{array}$ & $\begin{array}{l}\text { Aver.Con. } \\
\left(\mathrm{Bqm}^{-3}\right)\end{array}$ & $\begin{array}{l}\text { ED } \\
(\mathrm{mSvy})\end{array}$ & RRLC\% \\
\hline \hline Alsuqe Area & 15 & 23 & 84 & $52 \pm 6$ & $1.32 \pm 0.16$ & 1.047 \\
\hline \hline Frontal Area & 17 & 37 & 104 & $77 \pm 10$ & $1.95 \pm 0.26$ & 1.070 \\
\hline \hline Alhisynab Area & 19 & 36 & 159 & $98 \pm 10$ & $2.48 \pm 0.26$ & 1.090 \\
\hline \hline Hospital Area & 16 & 29 & 78 & $65 \pm 8$ & $1.64 \pm 0.21$ & 1.058 \\
\hline \hline Area number 6 & 17 & 27 & 95 & $59 \pm 8$ & $1.48 \pm 0.21$ & 1.052 \\
\hline \hline Area number 5 & 16 & 18 & 72 & $44 \pm 6$ & $1.11 \pm 0.16$ & 1.039 \\
\hline \hline Daim Lutfy Area & 18 & 37 & 106 & $73 \pm 8$ & $1.85 \pm 0.21$ & 1.066 \\
\hline \hline Alhila Aljadida Area & 15 & 26 & 98 & $61 \pm 6$ & $1.53 \pm 0.16$ & 1.054 \\
\hline \hline Overall & 133 & 18 & 159 & $66 \pm 8$ & $1.67 \pm 0.20$ & 1.059 \\
\hline \hline
\end{tabular}

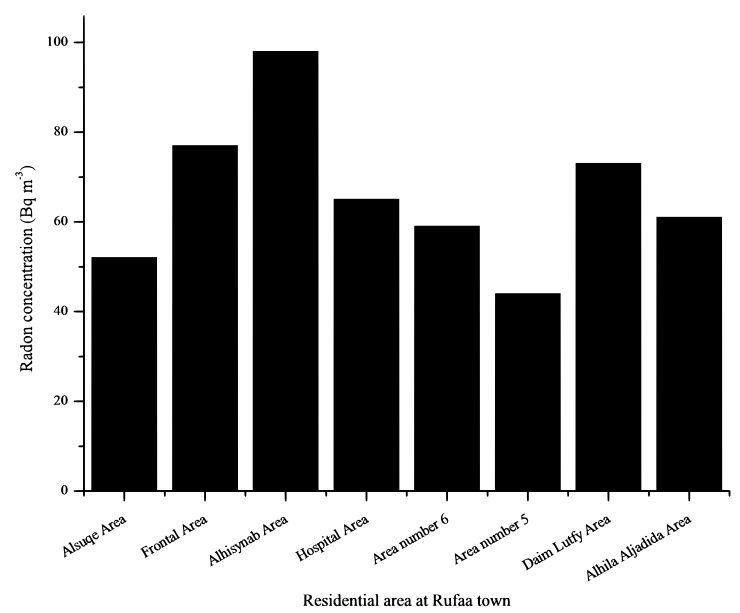

Fig. 5. Indoor radon concentration vs residential areas at Rufaa town.

to river terrace soils some of the inhabitants uses this soil in constructing their houses either directly or produce it as red bricks this may increase the indoor radon concentration at this area. It was found that since the flooding period, the Blue Nile River carries and drift a suspended material which re-sediments as silt clay, sandy clay, and sand and gravel [8].

The lower values of concentration value, effective dose (ED) and relative risk of lung cancer (RRLC), are recorded for the Eastern Area (Al-Hasahisa town) may be due to the reason of that, the area is an open small area situated in the external side of the town, the buildings are far apart with respect to each other, some buildings are constructed from strew and red bricks. The area is to some extent far away from the riverbanks, situated in an open flat area, so the area is good ventilated for this reason we found the lower values 


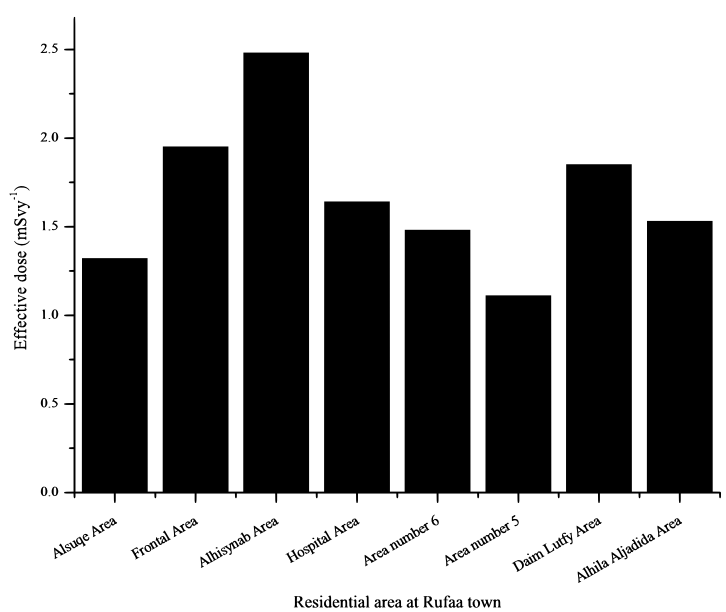

Fig. 6. Effective dose vs residential areas at Rufaa town.

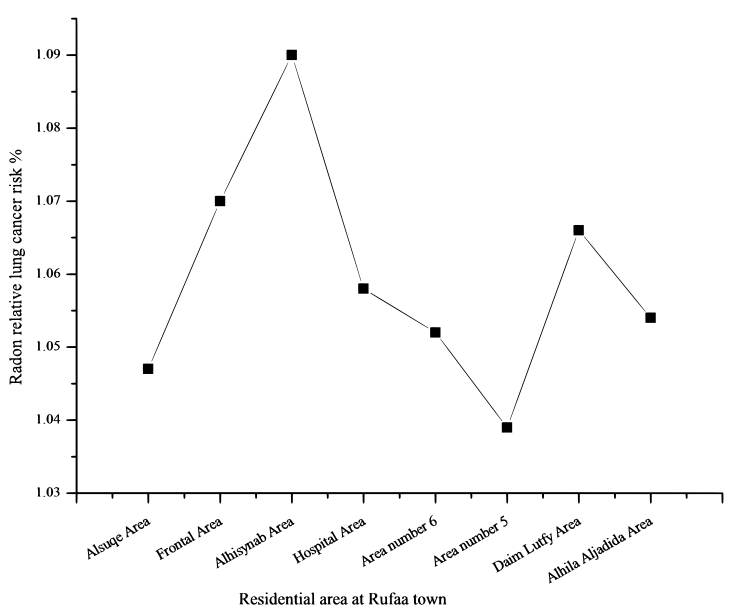

Fig. 7. Radon relative lung cancer risk vs residential areas at Rufaa town.

in our study. The lower values recorded for the Area number 5 (Rufaa town) may be due to the type of construction materials, which are mainly red brick and strew materials; these materials constitute low concentration values, rather than cement and concrete materials [11], for this reason the recorded values are minimum.

From our study we can find that the recorded values of indoor radon concentration are far below than the radon action level (200- 600) $\mathrm{Bqm}^{-3}$ as recommended by ICRP-1993 [19], lower than the new reference level $\left(100 \mathrm{Bqm}^{-3}\right)$ set by WHO [18] and below the action level $\left(148 \mathrm{Bqm}^{-3}\right)$ recommended by Environmental Protection Agency (EPA) [16]. The overall calculated average values for radon concentration in both towns are seen to be 
higher than the world-wide, population weighted, average radon of $40 \mathrm{Bqm}^{-3}$ as reported by UNSCEAR [1] and well within values reported for various locations in the Sudan and worldwide (Table 3 ). If we compare our concentration values in this study with national values we can find that (from Table 3) the recorded concentration values in Kassala, Halfa Aljdadida, Aroma and Kordufan are relatively higher values than the measured values in this study, while the recorded values for Khartoum, USA and Elmanagil are similar to that recorded for Rufaa town. As it is known that no intervention is required if the radon level is below $74 \mathrm{Bqm}^{-3}$, we can conclude and indicating that our calculated levels are safe for occupancy [27]. From the results we find that the average value of radon concentration in Rufaa town is lower than this level, but the average value of radon concentration in AlHasahisa exceeded this value, concerning this it is clear that in all probability the only intervention needed is to improve ventilation since it is well known that increased ventilation rate is an important factor in reducing indoor radon level [28].

From the results we can see that the average values of effective dose is found to be larger than the "normal" background level of $1.1 \mathrm{mSvy}^{-1}$; as quoted by UNSCEAR-2000 [1], less than even the lower limit of the recommended action level $\left(3-10 \mathrm{mSvy}^{-1}\right)$ as reported by the ICRP-1993 [19]. The obtained values of relative lung cancer risk for the two towns are seen to be comparable with other findings as shown in Table 3.

Table 3. Comparison of results with other results in various locations in the world

\begin{tabular}{|c|c|c|c|c|}
\hline Country(town) & $\begin{array}{l}\text { MeanConc. } \\
\mathrm{Bqm}^{-3}\end{array}$ & $\begin{array}{l}\mathrm{DE} \\
\left(m S v y^{-1}\right)\end{array}$ & $R R L C \%$ & Ref. \\
\hline Jordan & 32.4 & 0.46 & - & [2] \\
\hline Sudan(Khartoum) & 44.3 & 1.20 & - & [3] \\
\hline $\operatorname{Sudan}($ Kassala $)$ & 92.38 & 2.14 & 1.08 & {$[4]$} \\
\hline $\operatorname{Sudan}($ Aroma $)$ & 91.15 & 2.29 & 1.08 & {$[5]$} \\
\hline Sudan (Hal faAl jadida) & 94.2 & 2.36 & 1.09 & {$[5]$} \\
\hline Sudan (KhashmAlgirba) & 64.1 & 1.60 & 1.06 & {$[5]$} \\
\hline Pakistan & 138 & 3.94 & - & {$[6]$} \\
\hline $\operatorname{Sudan}($ Kordufan $)$ & 109.43 & 4.16 & - & {$[23]$} \\
\hline Sudan(Medani) & 57 & 1.40 & 1.051 & {$[24]$} \\
\hline Sudan $($ ElHosh $)$ & 50 & 1.30 & 1.045 & {$[24]$} \\
\hline Sudan (Elmanagil) & 45 & 1.20 & 1.040 & {$[24]$} \\
\hline Sudan(HajAbdallah) & 54 & 1.40 & 1.49 & {$[24]$} \\
\hline Sudan(WadAlmahi) & 41 & 1.10 & 1.037 & {$[24]$} \\
\hline SaudiArabia & 36.2 & 0.61 & - & {$[28]$} \\
\hline$U S A$ & 46 & - & - & [29] \\
\hline Brazil & 82 & - & - & {$[30]$} \\
\hline Italy & 52 & - & - & {$[31]$} \\
\hline India & 30.3 & 0.46 & - & {$[32]$} \\
\hline Sudan $(R u f a a)$ & 66 & 1.67 & 1.059 & Present study \\
\hline Sudan(AlHasahisa) & 86 & 2.18 & 1.078 & Present study \\
\hline
\end{tabular}




\section{Conclusion}

The average values of indoor radon concentration measured at Al-Hasahisa and Rufaa towns in the Gezira State - Central Sudan were below the action level recommended by ICRP. The ventilation rate in the buildings plays a very important role in the controlling of indoor radon concentration. Furthermore, the calculated effective dose is lower than the average value given by UNSCEAR and below the ICRP action level. Consequently, the relative lung cancer risk for radon exposure is low in these buildings and they can be considered safe when the hazardous health effects of radon are concerned.

Acknowledgements. The authors would like to express thanks to the residents of the study areas for their cooperation during the fieldwork.

\section{References}

[1] United Nations Scientific Committee on the Effects of Atomic Radiation (UNSCEAR), Sources and Effects of Ionizing Radiation, Vol. I Annex A: Dose Assessment Methodologies, United Nations, New York, 2000

[2] Al-Bataina, B. A., Elzain, A.-E. A., Seasonal variation of indoor radon-222 concentration levels in Zarqa City, Jordan, Abhath Al-Yrmouk "Basic Sci. \&Eng.". (2003)12, pp.191 202.

[3] Mukhtar, O. M. \& Elzain, A.-E. A., Radon Monitoring at Khartoum Using the Charcoal Technique, ABHATH AL-YARMOUK: "Basic Sci. \& Eng." 15(2006) 2, pp. 225-235.

[4] Elzain, A.-E. A., ET.AL., A Survey of Indoor Radon - 222 levels in Kassala town, Gezira J. of Eng. \& applied sci. 3(2008)2, pp .72- 100

[5] Elzain, A.-E. A., Indoor Radon-222 Concentration in Some Cities in Kassala State, Eastern Sudan, Proceedings of the 2011 International AARST Symposium, 2, (2011), pp.71-84.

[6] M. RafiQue, ET AL., Estimation of Annual Effective Radon Doses and Risk of Lung Cancer in the Residents of District Bhimber, Azad Kashmir, Pakistan, Nuclear Technology \& Radiation Protection, 26(2011)3, pp. 218-225.

[7] Elzain, A.-E. A., ET.AL., Measurements of Radon gas Concentration in a Soil at Some Towns in Kassala State, Gezira J. of Eng. \& applied sci.4(2009)1, pp .15 - 42.

[8] Elzain, A.-E. A., ET AL., Radium and Radon Exhalation Studies in Some Soil Samples from Singa and Rabak Towns, Sudan using CR-39, International Journal of Science and Research (IJSR),3(2014)11, 632- 637.

[9] Elzain, A.-E. A., Determination of Soil Gas Radon Concentration from some locations of Gedarif town, Sudan by CR-39, Nuclear Technology \& Radiation Protection, 32(2017)1, pp. 85-90

[10] Alshahri, F, El-Taher, A And Elzain, A.-E. A., Characterization of radon concentration and annual effective dose of soil surrounding a refinery Area, Ras Tanura, Saudi Arabia, J. Environ. Sci. Technol., 10(2017), pp. 311-319. 
[11] Elzain, A.-E. A., Radon exhalation rates from some building materials used in Sudan, Indoor and Built Environment, 24(2015)6, pp. 852-860.

[12] Elzain, A.-E. A., Measurement of Radon-222 Concentration Levels in Water Samples in Sudan, Advances in Applied Science Research, 5(2014)2, pp.229-234.

[13] Elzain, A.-E. A., A Study on the Radon Concentrations in Drinking Water in Kassala State (Eastern Sudan) and the Associated Health Effects, World Applied Sciences Journal, 31(2014)3, pp. 367-375.

[14] Banman, A, Hervat, D. J. And Lokobauer, N., In: Natural radiation environment (ed.) Vahra K J, Wiley Eastern, New Delhi, (1982)pp. 401-415.

[15] ***National Research Council. Committee on Health Risks of Exposure to Radon: BEIR VI. Health Effects of Exposure to Radon. National Academy Press, Washington, DC, 1999.

[16] Bochicchio, F., Radon epidemiology and nuclear track detectors: methods, results and perspectives, Radiat. Meas. 40(2005), pp. 177-190.

[17] USEPA , U.S. Environmental Protection Agency 2012 A Citizens Guide to Radon: The Guide to Protecting Yourself and Your Family from Radon, EPA 402/K-12/002, May 2012, www.epa.gov/radon.)

[18] ***World Health Organization (WHO). WHO handbook on indoor radon. A public health perspective. Switzerland: WHO Press, 2009.

[19] ***, Protection Against Radon at Home and Work, International Commission on Radiological Protection, ICRP Publication 65 Ann, ICRP 23, 1993

[20] Gulan, Lu. R. ET Al., High Annual Radon Concentration in Dwellings and Natural Radioactivity Concentration in Nearby Soil in Some Rural Areas of Kosovo and Metohija, Nuclear Technology \& Radiation Protection, 28(2013)1, pp. 60-67.

[21] Elzain, A.-E. A.,Seasonal variation of radon-222 concentration in shops and pharmacies of Alzarqa Town- Jordan, Proceedings of the 2011 International AARST Symposium, 2(2011), pp.38-45.

[22] Mansour, H.H. ET. AL., Measurement of indoor radon levels in Erbil capital by using solid state nuclear track detectors, Radiation Measurements, 40(2005)2-6, pp. 544-547.

[23] Hajo IdRISs, ET. AL., Characterization of 222Rn and Meteorological Parameters in Uro House at South Kordofan Stat, Indoor and Built Environment, 24(2014)5, pp. 650-657.

[24] ElzAin, A.-E. A., A Study of Indoor Radon Levels and Radon Effective Dose in Dwellings of Some Cities of Gezira State in Sudan, Nuclear Technology and Radiation Protection, 29(2014)4, pp. 307-312.

[25] Somogyi, G. ET. AL., Measurement of exhalation and diffusion parameters of radon in solids by plastic track detectors, Nucl. Tracks Radiat. Meas. 12(1986 )(1-6), pp. 701-704.

[26] LuBIN, J. H., AND BoICE, J. D., Lung cancer risk from residential radon meta-analysis of eight epidemiology studies, J. Nat. Cancer Institute, 89(1997)1, pp. 49 -57.

[27] ***, Why is Radon the Public Health Risk that it is? U. S. Environmental Protection Agency (US-EPA), http://www.epa.gov/ra don/aboutus.html (accessed 16 April 2014) 
[28] FARID, S. M., Indoor radon in dwellings of Jeddah city, Saudi Arabia and its correlations with the radium and radon, Indoor and Built Environment, 25(2014)1, pp. 269-278.

[29] Marcinowski, F., Na tion wide Sur vey of Residential Radon Levels in the US, Radiat. Prot. Dosim., 45(1992), 1-4, pp. 419-424

[30] CanobA, A., ET AL.,Indoor Radon Measurements and Methodologies in Latin American Countries, Radiat. Meas., 34 (2001), 1-6, pp. 483-486

[31] BochicCHIOA, F. ET. AL.,Annual average and seasonal variations of residential radon concentration for all the Italian Regions, Radiation Measurements, 40(2005) 2-6, p. 686-694

[32] Shakir Khan, M. ET. AL., The Study of Indoor Radon in the Urban Dwellings Using Plastic Track Detectors, Environmental Earth Sciences, 63(2011)2, pp .279-282 . 